\title{
I wonder if robots will take care of me when I am old: Positive aging representations of professionals working in health promotion services
}

Journal of Health Psychology

20I6, Vol. 2 I (I2) 2872-288।

(C) The Author(s) 2015

Reprints and permissions:

sagepub.co.uk/journalsPermissions.nav DOI: 10.1 I77/13591053/5587/41

hpq.sagepub.com

@SAGE

\section{Catrinel Craciun 1,2,3 and Uwe Flick'}

\begin{abstract}
How the social and institutional context is structured and represented by its actors has an impact on positive aging representations. This qualitative study explores professionals' views on positive aging, how they promote positive aging in their practice and what disparities occur between their discourses and the actual practice of promoting positive aging. Interviews were conducted with professionals from different active aging promotion services and analyzed with thematic coding. Findings show professionals hold negative views on aging while trying to promote positive views in their work, illustrating an existing theory-practice gap. Strategies used in practice can be integrated in existing agency models and inform interventions and active aging policies.
\end{abstract}

\section{Keywords}

health promotion services, positive aging representations, professionals, qualitative research

\section{Introduction}

Within an increasingly aged society, there are more professionals employed in various active aging promotion services. The developing service culture targeting aging includes health services, psychological counseling, social assistance, care services, and financial insurance agencies that should help guarantee wellbeing in old age and shape views on active aging (Stenner et al., 2010). Since most discourses about "the elderly" are constructed at a social and institutional level in welfare European states (Weicht, 2013), aging moves beyond being a personal issue, to becoming a public concern and challenge for policy development (Stenner et al., 2010).
Different discourses related to the increasing demand for services for an aging population are present in the literature. Some describe the rising number of elderly as a "silver tsunami" (Van Leuven, 2012); thus, pointing out

\footnotetext{
'Free University Berlin, Germany

2Jacobs University, Germany

${ }^{3}$ Babes-Bolyai University, Romania

\section{Corresponding author:}

Catrinel Craciun, Department of Qualitative Social and Educational Research, Faculty of Education and Psychology, Free University Berlin, Habelschwerdter Allee 45, I4I 95 Berlin, Germany.

Email: catrinelcraciun@yahoo.com
} 
the threat old persons may represent for existing health care and social services that cannot deal with the demands and expenses involved. Other representations range from vulnerable, dependent groups (Weicht, 2011) to "ageless" consumers of health and lifestyle services (Katz and Marshall, 2003) or reflect a sociocultural pressure to conform to youthful appearance norms to avoid negative stereotypes associated with looking older (Jankowski et al., 2014). Nevertheless, an active aging discourse is also present at the policy level, focusing on gains linked to aging (Lassen and Moreira, 2014). It implies healthy lifestyles, equal opportunities at the workplace, productive lifelong citizenship, social justice, anti-discrimination, and inclusion. This is in line with the western "agency" discourse, understood as the ability to act on the environment, to engender change in them and in others (Burr, 2003). Availability of choices is important followed by a person's capacity to enact those choices (Morgan et al., 2006) or control beliefs (Wiest et al., 2013). This "new aging" discourse has been criticized because it discriminates against people who are not fit in old age and mirrors consumerist ideas (Katz, 2005; Tulle, 2004). Also, high control beliefs associated with increased life satisfaction were shown to be related to higher mortality risk, since elderly falling in this category might overestimate their capacities or underestimate potential health threats (Wiest et al., 2013). Another focus in terms of aging discourse is the shift from public to private responsibility. Emphasis is placed on health maintenance rather than care (Minichiello et al., 2005) supporting the World Health Organization (WHO) policy focus on independence versus dependence, ability versus disability, and enjoyment versus endurance in old age (Lassen and Moreira, 2014). In Germany, the policy for older citizens values their active involvement and disease prevention through projects such as "Gesund älter werden" (WHO Europa, 2005) or encouraging volunteer work in old age (Komp et al., 2013; Konrath et al., 2012). Nevertheless, despite the proven relevance of positive views on aging for health in old age, no specific standards regarding how health professionals should promote these in their work exist in the German context (Tesch-Römer, 2012b).

Positive views on aging (i.e. perceiving positive meaning in old age, continuing to make plans) were proven to predict health in old age (Wurm et al., 2010). Since doctors and nurses are directly involved in the care of older citizens, their views on aging have been thoroughly researched. Findings from studies on student nurses showed they perceived older people negatively and used denigrating terminology (Walter et al., 2006). Research on images of aging in German doctors and senior care personnel (Flick et al., 2003) showed a predominance of negative views, characterizing old age by physical decline, memory loss, and increasing loneliness. More information is needed regarding representations of aging and how these affect the work of different categories of professionals in the field of aging. Moreover, studies on aging representations tend to focus on the need for treatment (Flick et al., 2012), but less is known about prevention services. Furthermore, there is a need to understand how professionals reflect on their views on aging and how they integrate them in their work.

\section{Aims and research questions}

Several professionals could play an important role in helping people invest old age with positive meaning. However, previous studies highlighted the existence of a gap between theory and practice (Elwell et al., 2013). Therefore, it becomes important to understand how practitioners try to translate their knowledge into practice. Since aging is a problem, professionals have to deal with themselves when promoting positive aging in their work; they may first have to deal with their own negative beliefs or fears related to old age. Starting from this premise, this study sets out to investigate the views on aging from a practitioner point of view and explore how they go about promoting positive aging in their work. 


\section{Methods}

\section{Data collection}

Data were collected by means of episodic interviews (Flick, 2014). The interview schedule targeted semantic and episodic knowledge alike. The first refers to information on abstract concepts and relations between these (e.g. what professionals understand as positive aging and how they relate heath behavior to positive aging). The latter refers to describing concrete situations reflecting people's experiences related to a topic (e.g. what kind of persons seek advice on positive aging, what kind of barriers are encountered in practice when trying to promote positive aging). Participants were asked to recount instances from their everyday professional lives related to the topic of positive aging. By describing instances from their work, they illustrated their representations of aging. Earlier studies have shown that episodic interviews help interviewed people to describe abstract concepts (e.g. definitions of positive aging as they have learned them in their training) and contextualize their experiences in view of their professional practices (Flick et al., 2003). The interview guide included 11 questions referring to their work in services targeting the aging population, representations about aging, what they do in order to promote old age, and what factors hinder or facilitate their work. To analyze the views on aging held by different categories of professionals, one question referred to how they define old age ("How do you identify someone as being old?"), and positive aging in particular, "What do you define as positive aging?" In order to capture their experiences of work situations where they have to deal with positive aging issues, they were asked, "what are you doing concretely in your work to promote positive aging? Can you give me some examples?"

\section{Participants}

The interviews with professionals are part of a larger project on resources for positive aging in precarious and financially secure individuals
(Craciun and Flick, 2014). Professionals were chosen to represent professions that work directly with old people or in services that have to do with preparation for old age. The exact categories were chosen based on what the middle-aged participants indicated would be an expert they would talk to about growing old and problems related to aging. The final categories were family doctor, insurance agent, psychologist, social assistant, and occupational therapist specialized in working with older people. Seven professionals (six women and one man) agreed to take part in this study: a family doctor, an insurance agent, three psychologists, one social assistant, and one occupational therapist. Participants were approached by the researcher at their workplace, informed about the aims of this study and provided with a consent form to sign if willing to take part in this study. A short demographic questionnaire was completed by each participant. Interviews were conducted by the first author of this study, between November 2012 and August 2013 and lasted between 40 and 90 minutes. Interviews were audio recorded and transcribed verbatim and reviewed for quality of the transcription.

\section{Data analysis}

The process of analysis was conducted following the principles of case specific thematic coding (Flick, 2014). This method was chosen as it was designed for comparative studies where the studied groups are defined already within the research question. The underlying assumption is that in different social groups, differing views can be found concerning the same topic that makes the subject of research. The analysis of interviews aimed at elaborating patterns of interpretations and practice in the statements of the professionals. All interviews were first analyzed as a series of case studies. All statements were coded for thematic areas (e.g. representations of aging) and for each case (each single interview). Second, comparative dimensions were identified for each case and used as a starting point to identify common aspects and differences between interviews. Based on these 
dimensions and their features, the cases were classified and analyzed for specific combinations of features. For instance, the analysis focused on how professionals represented aging or how they promoted positive aging in their practice. Similarities and differences between professions were identified in order to identify typologies of patterns of interpretations and practices, which were then analyzed in terms of their meaning contexts following the model of previous research (Flick et al., 2012).

\section{Results}

\section{Negative representations of old age}

In order to explore what professionals think about aging and old individuals, they were asked how they identify someone as being old.

\section{Aging as decline}

The interviewed professionals associate aging with mental and physical decline, "as you age you are losing skills, just as children are learning new skills, with aging you are losing these skills" (occupational therapist, f). Illness and disengagement from the world are described as characteristics of old age, "old is someone who is not healthy anymore and who experiences no joy in daily life ... this makes one old ... not having fun in life anymore ... work and interests keep one young" (occupational therapist, f). Decline is visible in the general loss of mobility and the shrinking of the living space, as "it becomes more difficult to move around, they (old people) do not dare to drive the car anymore ... they cannot climb the stairs as they used to ..." (general practitioner, f). Moreover, illnesses are associated with old age "I believe with old age come many illnesses that make one not able to function in the daily life ..." (psychologist 1, f). All professionals mentioned using physical appearance cues in order to place someone in the "elderly" category, namely having gray hair, wrinkles, and a tired posture.

\section{Patterns referring to the promotion of a positive old age}

A second aim of this study was to explore how the different categories of professionals try to promote positive aging in their work. Four main patterns were identified referring to staying mentally fit, taking responsibility for your aging process, staying socially engaged, and integrating technological means into the care services for the elderly.

Staying mentally fit. In the opinion of the professionals, an old person can compensate for the lack of physical abilities by remaining mentally fit (i.e. open to new things, mentally flexible, and curious). Flexibility is crucial for how one deals with change "the key point is to accept changes ... to perceive them as challenges not as loss ... this is flexibility of thought" (occupational therapist, f). According to the interviewed health psychologist, flexibility ensures finding solutions to deal with age-related changes and creativity in what concerns looking for optimization and compensation strategies.

Taking responsibility for positive aging. Interviewed professionals reported each individual is responsible for his or her own positive aging and should not "wait for help to be given" (social worker, f), but be proactive in seeking solutions and stay independent. Autonomy in this case means both deciding everything by yourself and delegating some tasks but keeping the freedom to choose how these are being done. For instance, "if you cannot do the shopping yourself you can still decide what is bought for you" (occupational therapist, f). Responsibility is understood by all interviewed professionals as being proactive and taking initiative, "wisdom is an outdated concept ... the decisive thing is how much a person thinks, participates ... if they seek advice with the young about computers ... that one exchanges ideas with young people ..." (general practitioner, f). Taking responsibility for ones aging process leads to staying independent in one's old age: 
I believe there are more possibilities nowadays to live an independent life in old age ... in the old days the family used to take responsibility and care for the old, but nowadays this is not the case anymore so old people need to be more independent. (occupational therapist, $\mathrm{f}$ )

While keeping one's autonomy means aging well, being dependent on others (i.e. family or senior care) is associated with fear and anxiety and thus needs to be avoided. All in all, when talking about their interactions in practice with aging persons, professionals expressed the wish to see more initiative on behalf of the service recipients, “... I would find it so nice if people would take more responsibility and would think about what should be done ..." (Insurance agent, f). Some participants expressed their faith in the generation that is aging at present, since compared to previous generations, "(they) are used to take care of themselves ... the generation aging now is much more strong-minded ..."(occupational therapist, f). However, social inequalities can arise since some persons cannot be independent in their old age. Due to lack of education or language skills (i.e. the case of aging immigrants), they would encounter more difficulties in staying active and independent in their older years, "people with a good education level or a good job are normally more independent ... those with poor education are more helpless ..." (social worker, f).

Being socially engaged. Even though autonomy is emphasized, having a good social network is considered part of positive aging by all interviewed professionals, "social networks are very important ... people who are alone have more fears ..." (general practitioner, f). Being engaged also means having a purpose in life despite older age, "that you still have fun in life that you have something for which to wake up each morning" (psychologist, f). It is argued that more community engagement in the process of positive aging is needed to compensate for the dangers of individualization that can lead to loneliness or exclusion of certain persons like those with Alzheimer. Social engagement by volunteering in the community also "provides the opportunity to feel needed" (health psychologist, f) and can help make positive aging possible for those who cannot afford it, "senior care personnel is lacking, money is lacking ... and public policy is always 20 years behind ... I cannot have positive aging without being able to afford good senior care and many cannot do this" (psychologist $2, f)$.

Integrating technology in coping with aging. Some participants described ways in which technology will provide new opportunities for applying compensation strategies, "many elderly already use audio books ... or mobile phones with big letters ... and the next aging generation will benefit even more from technology since they grew up with it ..." (occupational therapist, f). Social media can also help stay socially engaged and connected with different people, "For the aging generation it might be good to have virtual networks ... it allows one to stay connected with people" (psychologist 3, m). Nevertheless, some participants expressed their concern that technology might affect older individuals since they may not keep up with changes, "the pace of life has become quicker because of technology, through the technical changes, so that an older person can feel overwhelmed" (health psychologist, f).

\section{Reflection on own aging process}

Professionals reflected on their own views on aging and wondered about their own professional role in the context of changing times, "Sometimes I wonder when I will turn 80 and I will be ill ... will there be people to take care of me or will there be a factory with robots to take care of me ..." (psychologist 2, f). Furthermore, they talked about reflecting on the irrelevance of chronological age and trying to apply a positive thinking bias to deal with losses determined by their own aging as well as in their work context.

Irrelevant chronological age. All interviewed professionals agree that chronological age is only a conventional criteria used to place a person in a 
certain age group, "this is something decided by convention, that you say someone is old at 65 or 70" (health psychologist, f). Four participants mentioned retirement is not a criterion to describe old age since many people stay fit and active after they retire. However, participants emphasized psychological criteria (i.e. how mentally fit someone is, how active and engaged someone is), "there are people in their 80 s with all sorts of health problems ... who are still active and others who in their 70 s are very restricted in their actions ... it is not a question of biological age anymore ..." (family doctor, f). Therefore, the level of activity becomes a more important criteria than chronological age itself. Another important criteria is the level of autonomy, "I always check how autonomous a person still is, how much does he or she depend on others for help ... otherwise I would find it hard to define someone as old just based on their chronological age" (health psychologist, f). Several professionals mention the fact that the beginning of old age has shifted during the last decades from 70 to 80 or 85 "before I would have said 70, but now I would say 75 or 80 even as there are people in their 80 s who are very vital ..."'(psychologist 3, m). Therefore, being active is associated with not being described as "old," while loss of these qualities is linked to having entered old age. Old age is mostly understood as negative, with the positive aspect being that it occurs now later in life. Thus, 60 -year-old persons nowadays have the chance of still being perceived as young or as "active and young" and start being old only in their 80 s when they start losing their vitality.

Applying a positive thinking bias. One feature of the thought patterns related to positive aging mentioned by all interviewed professionals is focusing on "what I still can do and not on what I cannot do anymore" (social worker, f). Thus, interviewed professionals consider a positive thinking bias necessary to cope with the decline that is inherent in old age. Since changes are equated with losses, positive thinking is needed in order to cope. One important thing is to accept the loss of several abilities and interpret it not as loss, but rather as a change in your lifestyle ... to realize it does not function as it used to, but think that there are alternatives, it can work in another way. (occupational therapist, f)

In this context, compensation strategies are mentioned, "for instance if you find it difficult to remember things you just put more reminders around such as post its ..." (occupational therapist, f). According to some participants, a problem that they notice in practice is people's negativity and mention that this is one thing that needs to be changed in counseling, "People tend to concentrate on what they can't do anymore instead of seeing all the things that they can do" (general practitioner, f). Acceptance of loss and focusing on things that one can still do and on gains are mentioned as positive thinking

I don't get depressed when I can't do the things I used to do with 30 , but that I accept my age and try to be satisfied with my age ... that I see not only what I cannot do but also what I can do ... or the advantages, that I am more relaxed about things ... (social worker, $\mathrm{f}$ )

\section{Discussion}

This study explored how professionals from different services targeting positive aging promotion perceive aging themselves and how they try to promote positive aging in their work. Overall, results showed that when talking about aging and referring to their own experiences, professionals held mainly negative views on aging, associating it with decline and loss of abilities. This lends support to previous literature describing the negative aging stereotypes of health care practitioners (Adelman et al., 2000; Levy and Banaji, 2002). These negative stereotypes were shown to affect health communication and treatment adherence in older patients (Adelman et al., 2000). For instance, doctors' own fear of aging and lack of knowledge about aging processes may result in judgmental attitudes and misdiagnosis of some sensitive conditions in the elderly 
(e.g. experiences of abuse, depression, anxieties, and pains). Concerning health promotion interventions, it was shown that when professionals hold negative images of aging (i.e. old people are ill and need to rest, old people cannot change their lifestyles), they withhold from recommending preventive behavior such as physical activity (Ory et al., 2003). Nevertheless, present findings point that beside representations of loss and decline, interviewed professionals tend to invest old age with youthful characteristics (i.e. flexibility and mental fitness). By doing so, they might unintentionally set unrealistic standards for the people they counsel and thus indirectly influence their motivation to engage in positive aging interventions. Also, they might place too much emphasis on health aspects and thus confirm what was mentioned before as "healthism," namely an overemphasis on health in relation to aging (Crawford, 2006). Findings lend support to previous literature showing the decrease in importance of chronological age, the blurring of boundaries between middle-age and old age (Gilleard and Higgs, 2011), and confirm old age is socially constructed (Plath, 2008) reflecting a dichotomy of "what it means to be young" and "what it means to be old." This may result in the discrimination of some people because they are not keeping young and fit and have to deal with the burden of "growing old without aging" (Katz and Marshall, 2003). Nevertheless, it creates the possibility for professionals to help individuals to train their mental and physical abilities in order to stay and act young as long as possible. This also sets out the context for a positive aging counseling since it relies on the assumption that one can influence and control the aging process and prevent for instance morbidity in old age. Flexibility is seen as a component of positive aging by participants in this study and thus lends support to existing literature on coping flexibility (Rozanski and Kubansky, 2005), namely the ability to adjust goals to address changing circumstances, set limits to ones abilities, and ask for social support or advice. Compensation (see selection, optimization and compensation (SOC), Baltes and Smith, 2003; Freund, 2008) is one of the most frequently mentioned strategies that professionals promote in their work. This implies that they associate aging with loss and thus encourage the effective use of several compensation strategies. For instance, training one's mental abilities compensates for inevitable deterioration of ones physical abilities. Professionals mention applying a positive thinking bias to compensate for negative emotions that emerge due to decline and loss in old age. Promoting and developing wisdom is seldom mentioned or is described as an outdated concept by one of the interviewed professionals. This may come into conflict with views held by aging individuals, since previous research shows old people tend to describe wisdom as an advantage of growing old (Craciun and Flick, 2014) or a source of happiness in old age since it is associated with better emotional control (Yang, 2013). A great emphasis is placed on personal responsibility for designing ones positive old age, lending support to previous studies where health professionals highlight personal responsibility for health (Elwell et al., 2013). However, this kind of discourse can lead to blaming people for their illness (Todorova et al., 2006) or in this case failure to achieve successful aging. Taking responsibility may lead to independence in old age, while relying on family or institutions for help in old age generates dependence and thus, can result in "unsuccessful" aging (Hill, 2011). The notion of responsibility and pro-activity toward ones aging are in accordance with the agency discourse present in public policy (Jolanki, 2009) and active aging policy promoted by WHO or European Union (EU) (Lassen and Moreira, 2014) that encourage individual initiative to age in a healthy way. Based on the answers of several participants, practitioners tend to assume a guiding role rather than instructing people exactly how to age in a good way. They also expect people to be proactive, seek help, and come up with solutions by themselves. However, this attitude might lead to social and health inequalities in practice as some professionals pointed out that not all persons have the education level necessary for taking initiative. According to the interviewed participants, people who risk exclusion in this personal agency framework are immigrants, low educated 
people, and mini-jobers. Thus, more attention should be given to include, such groups in positive aging interventions.

Another way in which the agency discourse in reflected in the answers of interviewed professionals is by mentioning how the elderly might make use of technology while aging. The ways practitioners propose to integrate technology in old person's life points to a passive role of the user. This has been criticized in current research that tries to promote another approach of old persons as active consumers of technology (Peine et al., 2014). By assuming a proactive role in the design of the technology to help with aging processes may stimulate the potential for growth and resources that old persons can represent for society, as desired in positive aging discourses (Tesch-Römer, 2012a).

One limitation of this study is that it included a small number of participants from each category of professionals. However, the purpose of this study was not to compare the views of different professions and it also does not generalize the findings as representative for all professional categories involved. Furthermore, it represents a pilot study and should be further pursued with interviewing other members of the different professions on the topic of positive aging and how one should integrate this in the offered counseling services. Nevertheless, since positive aging services are complex and professional duties differ, one should have detailed accounts from different professions. For instance, those involves in prevention services could be interviewed separately from those involved mostly in aging care (e.g. dealing with dementia). This would give the opportunity to better explore barriers and facilitators, which various categories of professionals need to face in their work. An alternative would be to organize focus groups on the topic of the role of practitioners on positive aging from different professional expertise points of view since studies until now included mainly only one category of experts in focus groups. The role of multidisciplinary teams in the field of health in general is becoming more important (Patel et al., 2009). With the demographic changes such multidisciplinary teams become relevant for promoting positive aging. Psychologists need to work together with social workers and doctors and care personnel in order to help aging individuals and also their family. Thus, working in multidisciplinary teams becomes more and more relevant and thinking about the problem and about solutions should happen in a team.

This study brings its contribution to filling the theory-practice gap, by showing that several professionals involved in the preparatory services for old age hold knowledge on the theoretical models and policy regarding positive aging but struggle to find ways to translate this knowledge into practice. One possible barrier suggested by emerging themes from the interviews could be the fact that practitioners hold a negative view of aging themselves. Thus, one strategy for offering good quality services would be to change their own views and thus solve the discrepancy between what they believe and what they try to convey when working with aging individuals. However, positive aging policy recommendations point that images on aging should be inclusive and integrate both negative and positive aspects of old age (Tesch-Römer, 2012a). Thus, strategies based on the SOC model that professionals use in order to promote positive aging and to deal with their own aging processes may prove to be very effective. Nevertheless, in addition to the SOC model, they might also try to use strategies based on the positive aging model (Hill, 2011) in order to promote growth and development. Therefore, besides gratitude, altruism, and forgiveness interventions may include flexibility training, goal maintenance, wisdom training, and active use of technology for healthy aging. Moreover, information leaflets that stimulate critical reflection on one's views on aging (i.e. positive and negative aspects) can be integrated in the training of professionals working with the elderly. Furthermore, even though policy gives high priority to positive aging, as one participant stated, there are still few counseling services for aging adults as compared to services for young people. This 
shows that society overall still needs to adapt to the challenges of an aging population.

\section{Acknowledgements}

The authors thank the Alexander von Humboldt Foundation for supporting the first author of this study for conducting the current research

\section{Funding}

The study received a post-doc scholarship from the Alexander von Humboldt Foundation that made this research possible.

\section{References}

Adelman RD, Greene MG and Ory MG (2000) Communication between older patients and their physicians. Clinics in Geriatric Medicine 16: 1-24.

Baltes P and Smith J (2003) New frontiers in the future of aging: From successful aging of the young old to the dilemmas of the fourth age. Gerontology 49(2): 123-135.

Burr V (2003) Social Constructionism. London; New York: Taylor \& Francis.

Craciun C and Flick U (2014) "I will never be the granny with rosy cheeks": Perceptions of aging in precarious and financially secure middleaged Germans. Journal of Aging Studies 29: $78-87$.

Crawford R (2006) Health as meaningful social practice. Health 10(4): 401-420.

Elwell L, Povey R, Grogan S, et al. (2013) Patients' and practitioners' views on health behaviour change: A qualitative study. Psychology \& Health 28: 653-674.

Flick U (2014) An Introduction to Qualitative Research (5th ed.). London/Thousand Oaks, CA/Delhi: Sage.

Flick U, Fischer C, Neuber A, et al. (2003) Health in the context of being old-Representations held by health professionals. Journal of Health Psychology 8: 539-556.

Flick U, Garms-Homolová V and Röhnsch G (2012) "And mostly they have a need for sleeping pills": Physicians' views on treatment of sleep disorders with drugs in nursing homes. Journal of Aging Studies 26: 484-494.

Freund AM (2008) Successful aging as management of resources: The role of selection, optimization, and compensation. Research in Human Development 5: 94-106.

Gilleard C and Higgs P (2011) Ageing abjection and embodiment in the fourth age. Journal of Aging Studies 25(2): 135-142.

Hill RD (2011) A positive aging framework for guiding geropsychology interventions. Behavior Therapy 42: 66-77.

Jankowski GS, Diedrichs PC, Williamson H, et al. (2014) Looking age-appropriate while growing old gracefully: A qualitative study of ageing and body image among older adults. Journal of Health Psychology. Epub ahead of print 28 April 2014. DOI: $10.1177 / 1359105314531468$.

Jolanki OH (2009) Agency in talk about old age and health. Journal of Aging Studies 23: 215-226.

Katz S (2005) Cultural Aging: Life Course, Lifestyle and Senior Worlds. Peterborough, ON, Canada: Broadview Press.

Katz S and Marshall B (2003) New sex for old: Lifestyle, consumerism and the ethics of aging well. Journal of Aging Studies 17: 3-16.

Komp K, Van Kersbergen $\mathrm{K}$ and Van Tilburg $\mathrm{T}$ (2013) Policies for older volunteers: A study of Germany and Italy, 1990-2008. Journal of Aging Studies 27(4): 443-455.

Konrath S, Fuhrel-Forbis A, Lou A, et al. (2012) Motives for volunteering are associated with mortality risk in older adults. Health Psychology 31(1): 87-96.

Lassen AJ and Moreira T (2014) Unmaking old age: Political and cognitive formats. Journal of Aging Studies 30: 33-46.

Levy BR and Banaji MR (2002) Implicit ageism. In: Nelson TD (ed.) Ageism: Stereotyping and Prejudice Against Older Persons. Cambridge, MA: MIT Press, pp. 49-75.

Minichiello V, Sommerville M, McConaghy C, et al. (2005) The challenges of ageism. In: Minichiello $\mathrm{V}$ and Coulson I (eds) Contemporary Issues in Gerontology: Promoting Positive Ageing. Sydney, NSW, Australia: Allen \& Unwin, pp. $1-34$.

Morgan LA, Eckert JK, Piggee T, et al. (2006) Two lives in transition: Agency and context for assisted living residents. Journal of Aging Studies 20: 123-132.

Ory M, Hoffman MK, Hawkins M, et al. (2003) Challenging aging stereotypes strategies for creating a more active society. American Journal of Preventive Medicine 25: 164-171. 
Patel S, Peacock SM, Mckinley RK, et al. (2009) GPs' perceptions of the service needs of South Asian people with chronic pain: A qualitative inquiry. Journal of Health Psychology 14: 909-918.

Peine A, Rollwagen I and Neven L (2014) The rise of the "innosumer"- Rethinking older technology users. Technological Forecasting and Social Change 82: 199-214.

Plath D (2008) Independence in old age: The route to social exclusion? British Journal of Social Work 38(7): 1353-1369.

Rozanski A and Kubzansky LD (2005) Psychologic functioning and physical health: A paradigm of flexibility. Psychosomatic Medicine 67: 47-53.

Stenner P, McFarquhar T and Bowling A (2010) Older people and "active ageing": Subjective aspects of ageing actively. Journal of Health Psychology 16(3): 467-477.

Tesch-Römer C (2012a) Active Aging and Quality of Life in Old Age. Geneva: UNECE.

Tesch-Römer C (2012b) Promoting participation, social inclusion and non-discrimination of older persons. In: Key note address given at the UNECE ministerial conference on ageing, Vienna, 19 September.

Todorova I, Baban A, Balabanova D, et al. (2006) Providers' constructions of the role of women in cervical cancer screening in Bulgaria and Romania. Social Science \& Medicine 17: 776-787.

Tulle E (2004) Rethinking agency in old age. In: Tulle E (ed.) Old Age and Agency. New York: Nova Science Publishers, pp. 175-189.
Van Leuven KA (2012) Population aging: Implications for nurse practitioners. The Journal of Nurse Practitioners 8: 554-559.

Walter U, Flick U, Neuber A, et al. (2006) Alt und Gesund? Altersbilder und Präventionskonzepte in der ärztlichen und pflegerischen Praxis [Old and Healthy? Representations of Aging and Prevention Concepts in the Health Care Practice]. Wiesbaden: VS Verlag.

Weicht B (2011) Embracing dependency: Rethinking (in)dependence in the discourse of care. The Sociological Review 58(s2): 205-224.

Weicht B (2013) The making of "the elderly": Constructing the subject of care. Journal of Aging Studies 27: 188-197.

WHO Europa (2005) Gesund Älter Werden. Available at: http://www.deutscher-praeventionspreis.de (accessed 14 March 2014).

Wiest M, Schüz B and Wurm S (2013) Life satisfaction and feeling in control: Indicators of successful aging predict mortality in old age. Journal of Health Psychology 18: 11991208.

Wurm S, Tomasik MJ and Tesch-Römer C (2010) On the importance of a positive view on ageing for physical exercise among middle-aged and older adults: Cross-sectional and longitudinal findings'. Psychology \& Health 25: $25-42$.

Yang S (2013) Wisdom and good lives: A process perspective. New Ideas in Psychology 31: 194-201. 